\title{
Maximum Sustainable Yield, Maximum Economic Yield and Sustainability in Fisheries
}

\section{ISSN: 2578-031X}

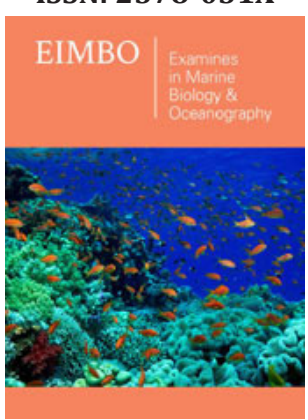

*Corresponding author: Ernesto A Chávez, Department of Evaluation and Modeling of Fisheries, Mexico

Submission: 觜 December 14, 2019

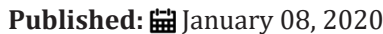

Volume 3 - Issue 3

How to cite this article: Ernesto A Chávez, Maximum Sustainable Yield, Maximum Economic Yield and Sustainability in Fisheries. Examines Mar Biol Oceanogr. 3(3). EIMB0.000561.2020.

DOI: 10.31031/EIMBO.2020.03.000561

Copyright@ Ernesto A Chávez, This article is distributed under the terms of the Creative Commons Attribution 4.0 International License, which permits unrestricted use and redistribution provided that the original author and source are credited.

\section{Ernesto A Chávez*}

Department of Evaluation and Modeling of Fisheries, Mexico

\begin{abstract}
A brief review of the concept of Maximum Sustainable Yield (MSY) used in fisheries management is discussed. The convenience of assessing the exploited stocks with the aid of simulation is advised, because implies the possibility to analyze the age structure of the fishery in more detail, as compared to the traditional methods of fish stock assessment. Emphasis is given to the use of the MSY as limit reference point because as long as the Fishing Mortality or fishing effort required for that point is kept at lower values, the fishery will have a good chance to be sustainable. A mention of the Maximum Economic Yield is made, proposing its use a target for the management, because it is reached in general with lower $\mathrm{F}$ values that for the MSY, and this way keeping the fishery in a healthy condition.
\end{abstract}

Keywords: Fishing mortality; Exploited stocks; Fisheries

\section{Introduction}

The use of some terms in fisheries science is of a common use, especially in cases of fisheries management. A constant concern by fisheries scientists is the problem of assessing the exploited stocks and devising accurate scenarios for their optimum and sustainable management Mace [1] and Maunder [2]. This problem becomes critical as long as more and more stocks are overexploited with every passing day, leading to economic crisis of groups of fishers depending on these fish resources.

\section{The Approach}

For assessing the stocks, an age structured simulation model was used, named FISMO (acronym of Fisheries Simulation Model), described by Chavez [3] and Chávez-Ortiz [4]. It is fed with catch data and population parameter values; it can be run with only biological data, as the growth rate parameter $(\mathrm{K})$, the asymptotic length $(\mathrm{L} \infty)$, the asymptotic weight $(\mathrm{W} \infty)$, which estimated by the model using the length (L)-weight (W) equation where its parameter values $\mathrm{a}$ and $\mathrm{b}$ must be provided too. In many worldwide fisheries, parameter values are available in the Fish Base Web page. With simple economic information like costs of a fishing day per boat, the number of boats fishing, and the value per kg of the catch at the landing time (without value added), the economic performance of the fishery can be also examined. It is a tool accessible for the users; aided by the population parameter values of each stock, the model transforms catch data and reconstructs the age structure over time, allowing the assessment of optimum biological and economical harvesting strategies under different management scenarios. These scenarios are addressed to evaluate the stock response after changing the Fishing mortality (F), which is directly proportional to the fishing intensity and the age of first catch (tc)

It allows the possibility to identify quantitative scenarios and to optimize the adoption of management regulations addressed to the identification of exploitation strategies. This would allow choosing the reduction of fishing effort to allow sufficient fish in the sea such that they could maintain the stock in a healthy condition, this is, enough number of adult fish capable to reproduce and maintain a relatively constant stock enough to supply a portion of the stock to be harvested by the fishery. 
By assessing the stocks with a simulation model that analyzes the age structure, MSY can be determined with the current tc and compared to the optimum MSY value as a function of tc. Then the difference between current MSY and optimum MSY is evaluated and unexploited potential yield is found. Based on the general principles of evaluation of fishery resources Beverton \& Holt [5]; Hilborn \& Walters [6], the management strategies can be tested to determine the effect of the effort on recruitment, biomass, capture and profits; these variables can be compared under different exploitation scenarios so several optimal scenarios for the fishery are defined. Current data on operating costs and benefits for fishing are used, and the exploitation scenarios can be simulated by modifying the age of first catch (tc) and the fishing mortality (F); with the results provided by simulation, it is possible to identify the most appropriate management strategy.

Adoption of management strategies is a prime concern by fishing authorities, because on their accurate decisions depends the conservation of fish stocks and the fisheries. A fishery is exploited sustainably as long as it allows being exploited for a long time. For the adoption of good management decisions, it is often based upon the reference points. Which are the bench marks used to compare the current status of a fishery respecting another status that can be a desirable reference. There are basically two types, target reference points and limit reference points Caddy \& Mahon [7].

A traditional way used to describe the reference points of a single fishery is the surplus yield model Schaefer [8], which roughly describes the effect of fishing intensity, equivalent to fishing mortality, on the stock biomass. This model is based on the assumption of a logistic growth of the population and its derivative describes the expected change in stock biomass as consequence of the fishing intensity; this change displays a parabolic trend, whose apex is known as Maximum Sustainable Yield (MSY). In principle, any fishery should not be exploited with a fishing pressure (usually the fishing mortality, F) such that its effects surpass the MSY level, if this is so, the population will not be able to replace its biomass as consequence of reproduction. For this reason, the FMSY level is considered a limit reference point which should not be surpassed, or otherwise the fishery will be overexploited or even collapsed. A collapsed stock is when its biomass is just $10 \%$ of the size it had once and adopted as reference.

There are other reference points Caddy \& Mahon [7]; Mace [9], but for the purpose of this paper, they will be not mentioned here. Let us say that for management purposes, the main goal in the analysis and assessment of any fishery will be to evaluate the MSY and then, by using this as reference, to identify which value of the $\mathrm{F}$ is causing this. The next step in the management process should be trying to apply the level of fishing effort responsible for that $\mathrm{F}$ value and then to reorient the fishery to meet this goal. It is very important to remind that the fisheries assessment must be carried on as a permanent procedure, otherwise any regulation applied may be wrong due to errors in the assessment process.

\section{Conclusion}

When an age structured model is used for the assessment, resulting curve of the stock biomass is not symmetrical, it usually describes an asymmetric curve biased towards the left side, but the MSY is clearly indicated. Other components of the fishery, like the number of boats and the number of fishers, describe curves with similar trajectory as the catch line, and the $\mathrm{F}$ at the maximum values of each of these variables is the same as that of the MSY. This is illustrated in Figure 1 showing the output of the bioeconomic variables of a fishery, where the trend line of the profits clearly indicate that the maximum value or Maximum Economic Yield (MEY), it is attained at a lower $F$ value than the one required for the MSY. This is a common trend observed in many fisheries; in a few cases, the FMEY coincides with the FMSY, but is never higher. For this reason, it is considered that its adoption could be a very convenient target in the fisheries management process, because it ensures not overfishing the fishery, and reduces the risk of undesirable environmental effects that may cause a wrong prognosis and therefore depletion of the fishery [10].

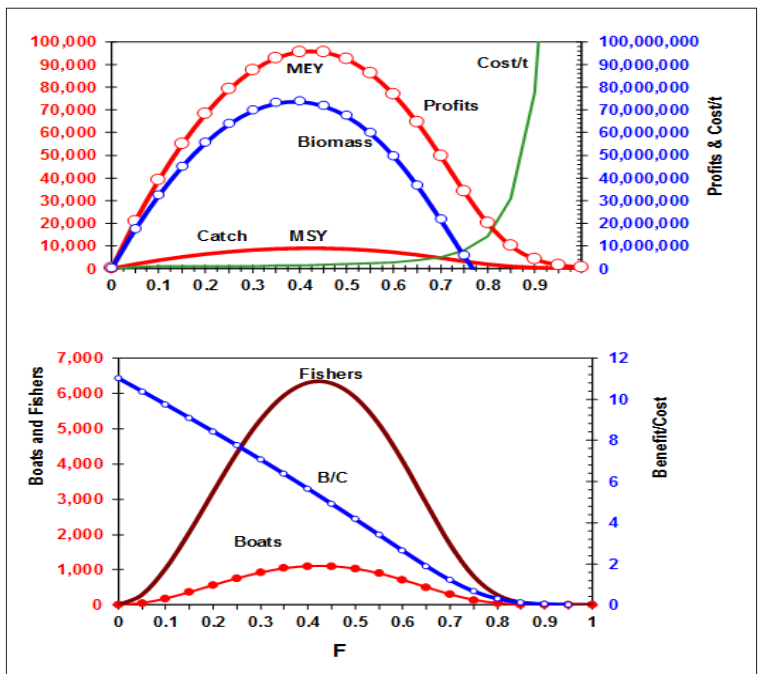

Figure 1: Trends of the yield, stock biomass, the number of boats, the number of fishers, the cost per $t$, benefit/cost ratio, profits, as a function of the fishing mortality in a brown shrimp fishery of the Gulf of California evaluated with a bioeconomic simulation model. The scale on the upper left side is tons. The MSY and the MEY are also indicated in the upper figure. 
The age of first catch is a factor with strong influence on the catch and on the status of an exploited stock. Since more than sixty years ago Beverton \& Holt [5] it is shown that the yield per recruit increases with the age of first catch, until the MSY is attained. However, many papers assessing fisheries were published afterwards and up to present time, just a few mention that by increasing the age of first catch by using nets with wider mesh openings, the age/size of fish being caught will be older, allowing juvenile fish scaping from being caught [11]. Doing this has several benefic consequences, because young fish would have a chance to reach the age of maturity, there would be more fish having chance to breed, and the stock biomass would be much higher than in an overexploited condition. In this case, fishers would have a chance to get higher yields and the stock would have more probability to be exploited under a sustainable condition. This process is illustrated in Figure 2.

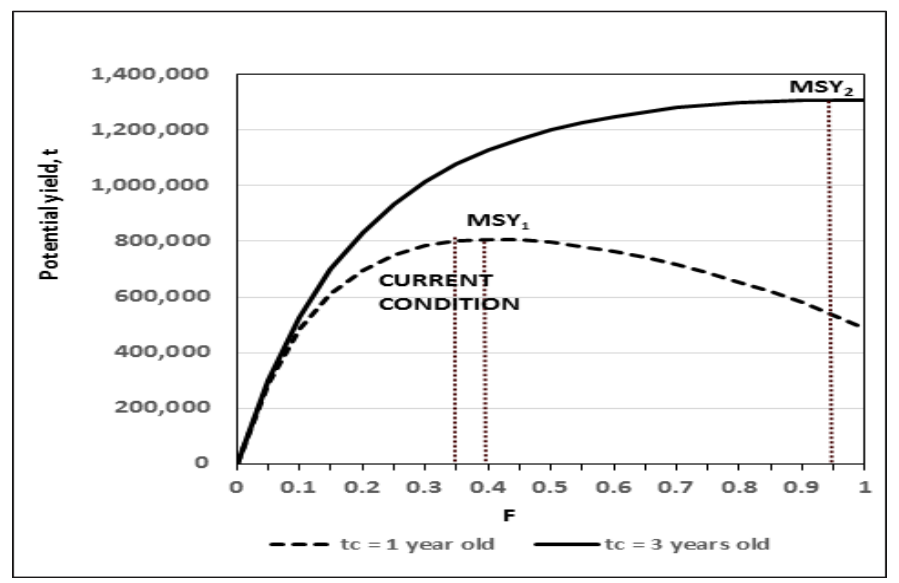

Figure 2: Stock response as consequence of the use of two ages of first catch, one and three years old. In the lower curve, the age of first entry to the fishery corresponds to juvenile fish with tc=1; in the higher curve, all fishes with tc=3, all exploited stock are adult fish, allowing the population to reach higher biomass. MSY2 and MSY2 correspond to the MSY values for each stage of the fishery. The example corresponds to the Gulf menhaden chosen as an example.

\section{Acknowledgement}

The author is holding a research grant from the Polytechnic Institute of México.

\section{References}

1. Mace P (1994) Relationships between common biological reference points used as thresholds and targets of fisheries management strategies. Can J Fish Aquat Sci 51: 110-122.

2. Maunder MN (2008) Maximum Sustainable Yield. Encyclopedia of Ecology.

3. Chávez EA (2005) FISMO: A generalized fisheries simulation model. In: Kruse GH, Gallucci VF, Hay DE, Perry RI, Peterman RM, et al. (Eds.), Fisheries assessment and management in data-limited situations. Alaska Sea Grant College Program, USA, pp. 659-681.

4. Chávez OEA (2014) A numerical model for the sustainable administration of fisheries. CICIMAR Oceánides 29(2): 45-56.
5. Beverton R, Holt SJ (1957) On the dynamics of exploited fish populations. Agric Fish Inv Ser 2(19): 533.

6. Hilborn R, Walters C (1992) Quantitative fisheries stock assessment: Choice, dynamics \& uncertainty. Chapman \& Hall, London, UK.

7. Caddy JF, Mahon R (1995) Reference points for fisheries management. FAO Fisheries Technical Paper 347: 83.

8. Schaeffer M (1954) Some aspects of the dynamics of populations important to the management of the commercial marine fisheries. Bull 1(2): 23-56.

9. Mace P (2001) A new role for MSY in single-species and ecosystem approaches to fisheries stock assessment and management. Fish and Fisheries 2(1): 2-32.

10. Larkin P (1977) An epitaph for the concept of maximum sustained yield. Trans Amer Fish Soc 106(1): 1-11.

11. Schaefer M (1954) Some aspects of the dymanic of populations important to the management of the commercial marine fisheries. Bull Inter Amer Trop Tuna Com 1(2): 23-56. 